\title{
ESTUDO COMPARATIVO ENTRE MÉTODOS DE COLORAÇÃO PARA A PESQUISA DO BACILO ÁLCOOL-ÁCIDO RESISTENTE EM SECREÇÕES PULMONARES
}

\author{
Clara Pechmann Mendonça * \\ Vera Lygia Ferreira Lourenço* \\ Mario Tsunezi Shimizu* \\ Paulo Roberto Natalino* \\ Ivone Shizuko Anno* \\ Romanoff Jorge S. Haddad ** \\ José Dario Prada** \\ Geraldo Campos Costa**
}

RSPU-B/241

MENDonç, C. P. et al. - Estudo comparativo entre métodos de coloração para a pesquisa do bacilo álcool-ácido resistente em secreções pulmonares. Rev. Saúde públ., S. Paulo, 9:7-10, 1975.

RESUMo: Apresentação do resultado comparativo entre dois métodos de coloração Osol e Ziehl-Neelsen para a pesquisa do bacilo álcool-acido resistente, em 337 amostras secrecão pulmonar. Foi realizada uma avaliação cultural de 287 amostras, mostrando que o método de Osol apresenta-se melhor nas baciloscopias discordantes e que há tendência em apresentar maior riqueza de germe.

UNITERMos: Tuberculose. Bacilo álcool-ácido resistente. Coloração.

\section{N T RODUCA O}

0 método de Ziehl preconizado em 1882 é o método de rotina, usado universalmente para a coloração de bacilos álcool-ácido resistentes.

Numerosas modificaçōes tem aparecido desde o método inicial de Erlich, como o de Kuhne, Hauser, Honrich, Weigert, Herman, Much Fontes ${ }^{3}$. $\mathrm{O}$ valor do método depende grandemente dos cuidados técnicos empregados, devendo sempre que se fizer alguma alteração usar cautela, evitando-se falsos resultados. Por esse método fazemos uma coloração de fundo utili- zando-se o azul de metileno, ácido pícrico ou mesmo o verde de malaquita.

Atualmente citam-se alterações maiores como coloração a frio usando-se a fucsina com detergente ("teepol", laurilsulfato ou "Tween 80") 1 .

No método de Osol usa-se o mesmo liquido de Ziehl para coloração do esfregaço, sendo totalmente descorado através do ácido sulfúrico e posterior lavagem com sulfito de sódio e álcool, não se utilizando coloração de contraste (Dents apud Suassuna e Pinheiro ${ }^{3}$ ).

* Faculdade de Farmácia e Odontologia de Araraquara, SP - Rua Expedicionários do Brasil, 1621 - Araraquara, SP - Brasil

** Sanatório Dr. Nestor Goulart Reis - Américo Brasiliense, SP - Brasil 
MENDONÇA, C.P. et al. - Estudo comparativo entre métodos de coloração para a pesquisa do bacilo álcool-ácido resistente em secreções pulmonares. Rev. Saúde públ., S. Paulo, 9:7-10, 1975 .

Segundo a observação de Suassuna e Pinheiro ${ }^{3}$, através deste método os bacilos podem ser visualizados com maior facilidade em esfregaços mais espessos e os resultados comparados com os do método de Ziehl são bastante concordantes.

Realizamos um estudo comparativo entre os dois métodos com escarro obtido do serviço de rotina do Sanatório Dr. Nestor Goulart Reis, com a finalidade de sentir as vantagens que oferecem, não só como métodos para avaliação da baciloscopia, mas também como técnicas de observação e preparação.

\section{MATERIAL E MÉTODOS}

O material usado foi a secreção pulmonar de pacientes hospitalizados no Sanatório Dr. Nestor Goulart Reis, de Américo Brasiliense, SP (Brasil), sendo entregue no laboratório em pequenos recipientes hermeticamente fechados.

Coletamos material de 337 pacientes sendo que as baciloscopias negativas em pelo menos 200 campos microscópicos, foram repetidas por 3 vezes em dias diferentes.

Os esfregaços foram sempre realizados por um único técnico, sendo sempre usados os mais espessos para o método de coloração de Osol.

A coloração de Ziehl-Neelsen, utilizando como contraste o azul de metileno e a observação das lâminas foi realizada nos Laboratórios do próprio Sanatório, como serviço de rotina.

A coloração de Osol (Dents apud Suassuna e Pinheiro ${ }^{3}$ ) realizada nos Laboratórios da Faculdade de Farmácia e Odontologia de Araraquara, SP (Brasil) seguiu a seguinte técnica:

a) Cobrir o esfregaço com fucsina de Ziehl e aquecer até quase ebulição por $31 / 2$ minutos. b) Descorar com solução aquosa de ácido sulfúrico a $10 \%$ até o esfregaço ficar transparente.

c) Lavar com mistura de 5 partes de solução de sulfito de sódio a $10 \%$ e uma parte de álcool a $96 \%$.

d) Lavar rapidamente com água e deixar secar sem contraste.

Logo após a obtenção dos esfregaços, o material era descontaminado pela adição de soda (método de Petroff).

Após a neutralização, 287 amostras foram semeadas em meios de cultura de Lowenstein-Jensen, seguindo-se as observações necessárias para verificação de contaminação ou crescimento de micobactérias.

As culturas foram examinadas semanalmente durante 8 semanas e anotados os caracteres macroscópicos para eventual pesquisa de micobactérias atípicas.

\section{RESULTADOS E DISCUSSÃO}

Verificamos que houve uma concordância de $89,89 \%$ entre os dois métodos, considerando-se também que entre os concordantes positivos foi observada maior riqueza de germes através do método de Osol.

Entre os discordantes, o método de Osol mostrou-se bem superior, pois revelou 30 amostras positivas $(8,93 \%)$ enquanto o método de Ziehl apenas 4 amostras (1,18\%) (Tabela 1).

Analisando a Tabela 2 verificamos que das 287 amostras de escarro semeadas em meio de Lowenstein-Jensen 237 (82,5\%) são concordantes nos dois métodos de coloração confirmados por cultura.

Das 23 discordantes mostrando o método de Osol baciloscopia positiva, 15 $(5,22 \%)$ confirmaram sua positividade através da cultura e entre as 4 positivas pelo método de Ziehl, uma $(0,34 \%)$ foi confirmada. 
MENDONCA, C.P. et al. - Estudo comparativo entre métodos de coloração para a pesquisa do bacilo álcool-ácido resistente em secreçóes pulmonares. Rev. Saúde públ., S. Pauio, 9:7-10, 1975 .

T A BELA 1

Comparação entre os métodos de coloração de Osol e Ziehl Neelsen em 337 baciloscopias

\begin{tabular}{c|c|c|c}
\hline \multicolumn{2}{c|}{ Concordantes } & \multicolumn{2}{c}{ Discordantes } \\
\hline+ & - & Osol + & Ziehl + \\
\hline $147(43,61 \%)$ & $156(46,28 \%)$ & $30(8,93 \%)$ & $4(1,18 \%)$ \\
\hline
\end{tabular}

T A B E L A 2

Comparação dos métodos de coloração de osol e Ziehl com resultados obtidos através de 287 culturas

\begin{tabular}{c|c|c|c|c}
\hline \multicolumn{2}{c|}{ Amostras } & Osol & Ziehl & Cultura \\
\hline 113 & 39,30 & + & + & + \\
124 & 43,20 & - & - & - \\
21 & 7,31 & + & + & - \\
15 & 5,22 & + & - & + \\
8 & 2,72 & + & - & - \\
3 & 1,10 & - & + & - \\
2 & 0,70 & - & - & + \\
1 & 0,34 & - & + & + \\
\hline
\end{tabular}

Duas amostras cuja baciloscopia foi negativa pelos dois métodos nos exames realizados em 3 dias consecutivos, apresentaram crescimento reduzido depois de 30 dias de incubação no meio de Lowenstein-
-Jensen. Verificamos que 21 amostras apresentaram-se positivas por ambos os métodos de coloração sem confirmação cultural até após 60 dias de incubação.

\section{CONCLUSAO}

1 - Nos esfregaços corados pelo método de Osol os bacilos álcool-ácido resistentes são mais facilmente visualizados.

2 - Pela facilidade de se poder observar esfregaços mais espessos a quantidade de germes observados nos casos positivos é maior pelo método de Osol.

3 - Em nossos achados os resultados obtidos pelo método de Osol foram melhores nas discordâncias, inclusive com confirmação cultural.

4 - Apesar das grandes vantagens do método e da nossa sugestão para o seu uso ao lado do método de Ziehl, observamos que em serviços rotineiros, onde o número de esfregaços é bastante elevado, o método de coloração de Osol, por ser sem contraste de fundo, torna-se cansativo para o observador. 
MENDONCA, C.P. et al - Estudo comparativo entre métodos de coloraço para a pesquisa do bacilo álcool-ácido resistente em secrecóes pulmonares. Rer. Saúde públ., S. Paulo, $9: 7-10,1975$.

RSPU-B/241

Mendonça, C. P. et al. - [ A comparative study between two staining methods employed in the search of alcohol acid resistant bacilli in pulmonary secretions.] Rev. Saúde públ., S. Paulo, 9:7-10, 1975.

Sumary: The comparative results obtamed with the study of two staining methods, the Ziehl-Neelsen and the Osol ones, are presented. The study was performed with the alcohol acid resistant bacilli of 337 pulmonary secretion specimens. Evaluation cultures of $28 \%$ of these specinens were made. The Osol method proved to be better than the Ziehl-Neelsen one when dealing with discordant baciloscopic evalence. There tended to be a larger ammount of bacilli, too, when the former was used.

UNITERMS: Tuberculosis. Alcohol-acid resistant bacilli. Straing method.

\section{REFERENCIAS BIBLIOGRAFICAS}

1 ANDRADE. L. - Diagnóstico bacteriológico da tuberculose. Rer. de Hicrobiol., $1: 43-60,1970$.

2 DOPTER, C. \& SAQUEPPE, E. - Precis de bacteriologie. $3^{\mathrm{m}}$ ed. Paris, Baillière, 1926-27, \&. 2. p 8-19-52.
3 SLASSLNA, I \& PINHEIRO, J. - Comparação do método de Osol como método de Ziehl-Neelsen para baciloscopia na tuberculose Rer. bras. Pat. clin., 9:48-9, 1973 .

Recebido para publucasio em 13-11-rit Aprovado para publicacáo em 13-01-ro 